\title{
Reorganization of a hospital catering system increases food intake in patients with inadequate intake
}

\author{
Morten Freil', Michael Allerup Nielsen², Camilla Biltz², \\ Rikke Gut', Bent Egberg Mikkelsen ${ }^{3}$ and Thomas Almdal ${ }^{4,5}$ \\ 'Unit of Patient Evaluation, County of Copenhagen, Denmark; ${ }^{2}$ Hospitalkitchen and ${ }^{4}$ Department of Endocrinology J, \\ Herlev University Hospital, Denmark; ${ }^{3}$ The Danish Veterinary and Food Administration, Denmark; ${ }^{5}$ Department of \\ Endocrinology, Hvidovre University Hospital, Denmark
}

\section{Abstract}

Background: Low food intake is a frequent problem in undernourished hospital patients.

Objective: To study whether a reorganization of a hospital catering system enabling patients to choose their evening meal individually, in combination with an increase in the energy density of the food, increases the energy and protein intake of the patients.

Design: Observational study comparing the food intake before and twice after the implementation of the new system, the first time by specially trained staff and the second time by ordinary staff members, following training. The amount of food served, eaten and wasted was measured, and energy and protein intake calculated.

Results: The quartile of patients with the lowest energy intake consumed on average $128 \mathrm{~kJ}$ per patient [ $(95 \%$ confidence interval (CI) 79-178 kJ] with the old system; with the new system they consumed $560 \mathrm{~kJ}$ per patient $(95 \% \mathrm{CI} 489-631 \mathrm{~kJ})$ on the first occasion, and $1021 \mathrm{~kJ}$ per patient $(95 \% \mathrm{CI} 939-1104 \mathrm{~kJ})$ on the second occasion. With the old system, the wastage was on average $276 \mathrm{~g}$ per patient $(48 \%$ of the total amount produced) compared with $118 \mathrm{~g}$ per patient $(30 \%)$ and $78 \mathrm{~g}(21 \%)$ on the two test occasions with the new system.

Conclusions: Reorganization of a hospital catering system can increase energy and protein intake and reduce waste substantially.

Keywords: hospital food; nutritional risk; undernutrition

Received: 22 Nov. 2005; Revised: 9 Mar. 2006; Accepted: 7 Apr. 2006

\section{Introduction}

Among patients admitted to hospital there is a group who can be classified as being at nutritional risk. This means that the patients' nutritional status and/or their spontaneous energy intake, combined with the severity of the disease with which they are admitted, may increase the morbidity and the length of stay (1). A recent meta-analysis suggests that increasing the food intake in these patients reduces complication rates, mortality and length of hospital stay (2).

McWhirter and Pennington reported in 1994 that $40 \%$ of the patients admitted to a hospital were undernourished, and that $75 \%$ of the undernourished patients who remained in hospital for more than 1 week lost further weight (3). In a study from a Danish district general hospital, the amount of food ordered corresponded to $140 \%$ of the patients' calculated energy need; however, on average the patients only consumed an amount corresponding to $60-70 \%$ of their energy need, thus resulting in a very substantial waste (4). In the same study it was found that the patients at nutritional risk had the lowest food intake. Similar results have been reported in another Danish study (5) and in studies from England (6) and Switzerland (7).

These studies illustrate two problems that are probably seen in many hospitals in Europe: The amount of food produced is larger than the actual requirement of the patients, but in spite of this, a number of the patients, often those at nutritional risk, do not have their energy and protein require- 
ments covered, and moreover a substantial amount of food is wasted. Thus, measures aiming at increasing the food intake and reducing the waste are warranted.

At Herlev University Hospital the catering system for the evening meal was previously a system with a fixed menu. The food was put on the plate in the kitchen and transported to the patients in the various wards. The present study examined whether a change in the catering system for the evening meals, enabling the patients to some extent to choose their meals individually, in combination with a change in the meal towards higher energy density, could increase the energy and protein in patients with low intake, and at the same time reduce waste. The new system was examined on two occasions. The first occasion was a pilot period where the food were served by specially trained staff form the kitchen, and the second occasion was about 2 years after the new system had been implemented as a standard throughout the hospital.

\section{Material and methods}

\section{Menus and service}

The ways in which the menus were produced and presented to the patients with the old system and the new system are described below.

Old (fixed menu) system. The aim of food delivery systems in Danish hospitals is that each of the three main meals, i.e. morning, midday and evening, covers $20-25 \%$ of the total energy need, while snacks, in total, cover a maximum of about $30 \%$ of the energy need.

The staff on the wards decided which of the following three menus was most appropriate for the patients: a normal menu with a fat content corresponding to $30 \%$ of the energy $(E \%)$, a standard hospital menu with $40 E \%$ fat, or a menu for patients at nutritional risk with $50 E \%$ fat. The recommendation to the staff was primarily to use the standard hospital menu. For patients with diabetes and/or heart disease the normal $30 E \%$ menu was recommended, and for patients at nutritional risk the menu with $50 E \%$ fat was recommended. All three menus could be ordered corresponding to a $24 \mathrm{~h}$ energy intake of 7,9 or $12 \mathrm{MJ}$. The menu chosen was ordered, then produced in kitchen and delivered to the wards in the hospital.
In the kitchen the food was produced according to a fixed plan, which meant that the patients had no possibility of individualizing their choice of menu. Following cooking, a fixed portion of the food was put on plates in the hospital kitchen and was subsequently transported to the wards and served to the patients.

Individualized (new) system. Initially a survey and reorganization of the menus produced in the kitchen was undertaken. In co-operation with a professional catering company, Rasmus Bo Bojesen Aps, the menus were changed, aiming for an appetising look and aiming to minimize the size of the individual portions, i.e. the energy density was increased. The increase in energy density was in general obtained by adding a higher amount of fat, primarily from dairy products. It was stated that the cost of the ingredients should be the same as under the old system, corresponding to a price of approximately 1.30 euros per portion.

Production was organized so that for the evening meal, which is traditionally hot and the main meal in Denmark, the individual patient could choose from a menu-cart offering as a minimum one first course, two main courses and two desserts.

The menu always included a first course, a main course and a dessert, all with a fat energy content of $40-45 \%$. The energy content in each of these portions was $1000-1500 \mathrm{~kJ}$ per patient. This meant that the amount of energy in the evening meal depended on how many courses the individual patient chose. If for example the patient chose a full meal, including a first course, a main course and a dessert, the total energy content of the meal was 3-4000 kJ. If the patient chose a main course and either a first course or a dessert, the total energy content was about $2000 \mathrm{~kJ}$.

The menu always included a main course with $30 E \%$ fat and fresh fruit as an option for dessert, which meant that if a patient chose this combination, the total energy content was approximately $1500 \mathrm{~kJ}$. This combination was for groups of patients who required a meal with a relatively low fat energy content, and who were not severely catabolic, e.g. people with ischaemic heart disease or some patients with diabetes.

The menus were the same in study periods 2 and 3 (see below). The changes described only applied to the evening menus, and no other changes to the 
Table I. Mean amount of food delivered to the wards, mean amount of food eaten, and mean amount of food returned and not eaten (and thus wasted) during three study periods

\begin{tabular}{|c|c|c|c|}
\hline & \multicolumn{3}{|c|}{ Amount of food $(\mathrm{g})$ (\% of food delivered) } \\
\hline & Ist period & 2nd period & 3rd period \\
\hline Amount delivered per patient & 580 & 394 & 379 \\
\hline Amount eaten per patient & $305(52)$ & $276(70)$ & 301 (79\%) \\
\hline Amount not eaten and wasted per patient & $276(48)$ & $118(30)$ & $78(21 \%)$ \\
\hline
\end{tabular}

Period I: prefixed meals; period 2: possibility of composing the meal individually served by specially trained staff; period 3: possibility of composing the meal individually served by routine staff. All figures are given as grams per meal per patient.

catering system were introduced during the study periods.

\section{Study of intake of energy and protein}

Three hospital wards were included in the study: a gynaecological ward, a ward specializing in breast surgery and an orthopaedic surgery ward.

The study was carried out during three different periods:

- Period 1: the patients had their meals served according to the old system.

- Period 2: the patients had their evening meals served according to the new system. This was a pilot study in the three wards mentioned above. In this study period the options on the menu were presented to the patients every day, either by staff from the kitchen, i.e. two of the authors of the present study (MAN and CB), or by specially trained staff members on the three wards.

- Period 3: the patients had their evening meals served according to the new system. This part of the study was performed approximately 2 years after the new system had been implemented on all wards in the hospital, and about 2.5 years after the pilot study had been performed. As part of the implementation general information had been given to the various wards, but how the various wards informed and trained their staff was up to the head nurse and chief physician on the individual wards. In this study period the options on the menu were presented to the patients every day by members of staff on the three wards.

All three study periods were of 14 days' duration. During each period the amounts of food served to and wasted by the individual patients at the evening meal in the period were weighed and recorded. This allowed for both wastage and nutritional intake (energy and protein) to be calculated. Energy and protein intake was calculated with the MasterCater system. In this system all the menus used in the hospital kitchen are recorded and it is possible to calculate individual values for energy and protein intake and waste for each meal and patient.

The registration was carried out for a total of 969 patients: 376 in period 1, 328 in period 2 and 265 in period 3. In all three periods about $90 \%$ of all patients admitted to the wards were included in the study.

Unfortunately, no attempts were made to register diagnosis, age, weight or nutritional risk score of the patients.

\section{Patient experience and satisfaction}

During each of the three study periods approximately 70 randomly selected patients answered a questionnaire concerning the food served (see Table 2).

\section{Statistical methods}

In the three periods studied the results were grouped in four quartiles with respect to the calculated energy intake. The first quartile included the $25 \%$ with the lowest energy intake, the second quartile included the $25 \%$ with the second lowest energy intake, the third quartile included the $25 \%$ with the second highest energy intake, and the fourth quartile included the $25 \%$ with the highest energy intake. The mean energy and protein intakes in the four quartiles were calculated.

The total amount of food delivered to the wards, and the amounts eaten and left uneaten per patient were calculated in the two periods.

Groups were compared by unpaired $t$-test, and $p<0.05$ was considered statistically significant. 
Table 2. Answers to four questions regarding patients' experience and satisfaction with the evening meals served as a prefixed meal (first period), and to the same questions with the evening meal served in a way where the person can to some extent individually decide on the meal (second period)

\begin{tabular}{|c|c|c|c|c|c|c|c|}
\hline \multirow[t]{2}{*}{ Period: } & \multicolumn{3}{|c|}{ No. of patients } & \multicolumn{4}{|c|}{ Positive answers (\%) } \\
\hline & 1 & 2 & 3 & 1 & 2 & 3 & $p$ \\
\hline $\begin{array}{l}\text { How would you characterize the appearance of the main course? } \\
\text { (Positive: very good/good; negative: bad/very bad) }\end{array}$ & 68 & 71 & 60 & 75.0 & 93.0 & 82.8 & 0.005 \\
\hline $\begin{array}{l}\text { How appropriate was the quantity of food in your evening meal? } \\
\text { (Positive: appropriate; negative: too much/too little) }\end{array}$ & 67 & 70 & 59 & 61.2 & 80.0 & 77.6 & 0.016 \\
\hline $\begin{array}{l}\text { How did the food served at the hospital taste compared to the food you eat at home? } \\
\text { (Positive: much better/better/the same; negative: worse/much worse) }\end{array}$ & 65 & 72 & 60 & 43.1 & 79.2 & 46.4 & $<0.001$ \\
\hline $\begin{array}{l}\text { How satisfied are you with the evening meals served at the hospital in general? } \\
\text { (Positive: very satisfied/satisfied; negative: unsatisfied/very unsatisfied) }\end{array}$ & 64 & 73 & 59 & 78.1 & 95.9 & 76.3 & 0.002 \\
\hline
\end{tabular}

\section{Results}

In period 1 data were collected from 376 patients, in period 2 data from 328 patients, and in period 3 from 265 patients. In all three periods about $50 \%$ of the observations were obtained from the orthopaedic surgery ward, about $35 \%$ from the gynaecological ward, and about $15 \%$ from the breast surgery ward.

The mean energy intake grouped in the four quartiles in the three periods is shown in Fig. 1. Patients in the lowest quartile demonstrated a significant increase $(p<0.05)$ in the energy intake from $128 \mathrm{~kJ}$ per patient $[95 \%$ confidence interval (CI) $(79-178 \mathrm{~kJ}$ in period 1 to $560 \mathrm{~kJ}$ per patient $(95 \%$ CI $489-631 \mathrm{~kJ})$ in period 2, and further from period 2 to period 3 where the intake was $1021 \mathrm{~kJ}$ per patient $(95 \%$ CI $939-1104 \mathrm{~kJ})$. In the second quartile no significant change was seen from the first to the second period, whereas there was a significant increase of $400 \mathrm{~kJ}$ per patient from the second to the third period. Patients in the third quartile had an energy intake of about $2000 \mathrm{~kJ}$ in all

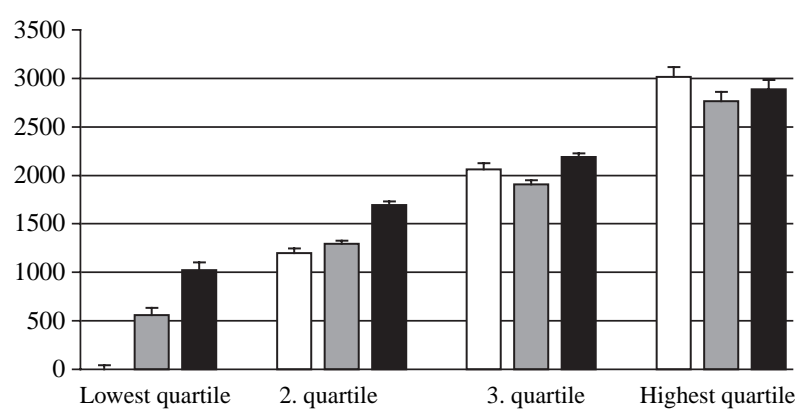

Fig. 1. Mean energy intake per patient (mean with $95 \%$ confidence limits) divided into four quartiles in relation to the energy intake. Results are given for period 1 (white bars, prefixed meals), period 2 (grey bars, possibility of composing the meal individually served by specially trained staff), and period 3 (black bars, possibility of composing the meal individually served by routine staff). three periods, while patients in the fourth quartile had an energy intake of $2400-2500 \mathrm{~kJ}$ in all three periods.

Figure 2 shows the mean protein intake in the four quartiles in the three periods. In the lowest quartile significant increases $(p<0.05)$ were seen, from $0.7 \mathrm{~g}$ per patient in the first period to $4.1 \mathrm{~g}$ in the second period and subsequently to $8.1 \mathrm{~g}$ in the third period. In the second quartile no changes were seen from the first to the second period, while a significant increase to $20.1 \mathrm{~g}$ was seen from the second to the third period. Patients in the third quartile had a protein intake of $18-25 \mathrm{~g}$ in all three periods and patients from the fourth had a protein intake of $25-35 \mathrm{~g}$.

In the first period a mean of $580 \mathrm{~g}$ of food per patient per evening meal was produced, $304 \mathrm{~g}(53 \%)$ was eaten and the rest was wasted. In the second period a mean of $395 \mathrm{~g}$ of food per patient per evening meal was produced, $276 \mathrm{~g}$ was eaten $(70 \%)$

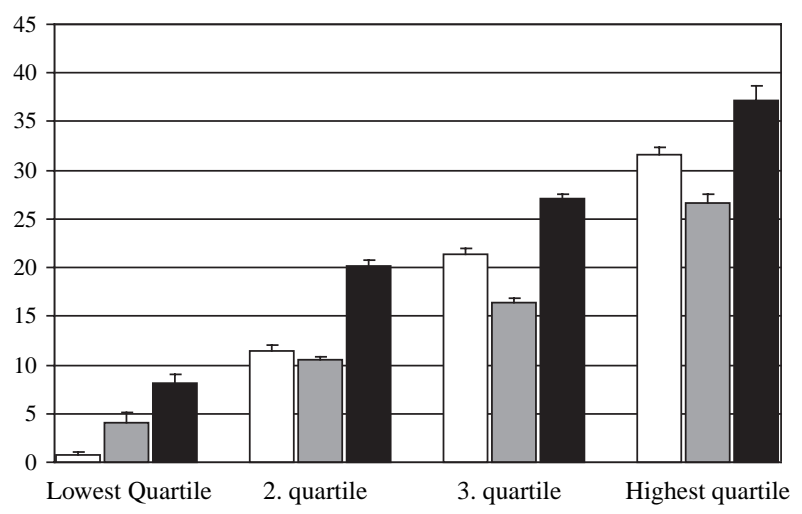

Fig. 2. Mean protein intake per patient (mean \pm SEM) divided into four quartiles in relations to the energy intake. Results are given for period 1 (white bars, prefixed meals), period 2 (grey bars, possibility of composing the meal individually served by trained staff), and period 3 (black bars, possibility of composing the meal individually served by untrained staff). 
and the remainder was wasted $(30 \%)$ (Table 1$)$. In the third period a mean of $379 \mathrm{~g}$ per patient per evening meal was produced, of which $301 \mathrm{~g}(79 \%)$ was eaten and only $78 \mathrm{~g}(21 \%)$ was wasted. Thus, from period 1 to period 3 the amounts of food produced and wasted were reduced by approximately $35 \%$ and $72 \%$, respectively.

Table 2 reports the experience and satisfaction of the patients with the two systems. The patients were fairly positive about the old system and very positive about the new system on both occasions.

\section{Discussion}

The main conclusion from this study is that it is possible to increase the energy and protein intake from the evening meal in a group of patients with the lowest energy intake by a combination of three factors: an increase in the energy density of the food served, allowing the patients to choose their own menu, and training the hospital staff.

The present study has some drawbacks. It is an observational study, which includes changes at three levels. Therefore, it is not possible to specify whether it was the combination of these factors or only one of these that resulted in the changes. In the study no attempt was made to assess whether the patients were at nutritional risk, and weight changes, morbidity and length of hospital stay were not registered. However, it has been reported from several studies that patients at nutritional risk are often those who eat the least $(2-5)$. For this reason, the results were examined in quartiles according to increasing amount of energy intake. Finally, the study only included observations of food intake in relation to the evening meal.

As mentioned previously, the aim of the food delivery system in Danish hospitals is that the energy content of the evening meal should cover $20-25 \%$ of the total energy intake. In an investigation carried out in a general district hospital (4), the calculated mean energy need was approximately $8000 \mathrm{~kJ}$ per day, indicating that the evening meal should contain $1500-2000 \mathrm{~kJ}$ to be sufficient to maintain the energy balance. In the present study, the change in the catering system led to a significant increase in the quartile with the lowest energy intake, resulting in an energy intake of $1000 \mathrm{~kJ}$ per patient per meal. This suggests that approximately $50 \%$ of the energy need is covered with the new system, while the old system only covered around $10 \%$. Patients in the second quartile demonstrated an increase in energy intake of approximately $500 \mathrm{~kJ}$ per meal to a total amount probably corresponding to the desired intake. The two quartiles with the highest energy intake took $2000 \mathrm{~kJ}$ or more, varying somewhat between the three periods, but generally $2000 \mathrm{~kJ}$ per meal per patient or more.

Only a few studies have focused on whether changing factors such as energy density and service affect energy intake. In one Swedish (8) and one English (9) study the energy density was increased. This was achieved by adding higher amounts of fat, which means that although the patients quantitatively do not eat more, the amount of energy intake is increased. In both studies it was found that the energy intake could be increased significantly in elderly people with a low food intake. When the present study was planned the focus was on preparing the meal so that it did not appear huge, and as can been seen from Table 2 close to $80 \%$ of the patients in periods 2 and 3 answered that they considered the quantity of food served to be appropriate. The energy density was increased, resulting in the appearance of smaller portions, and this probably explains some of the increase seen from period 1 to period 3. Another important factor is that the patients can choose their own menu to some extent, and this is reflected in the fact that $95 \%$ of patients in periods 2 and 3 were satisfied with the new system in general. Finally, the increase in food intake from the second to the third period probably reflects an effect of focusing the attention of the ward staff on the importance of nutrition. In this respect, a recent intervention study in three Danish hospitals, with focus on nutrition had been a theme for a minimum of 1 year, reports that patients at nutritional risk but assigned to the control group of the study had an energy intake of $84 \%$ of their calculated requirements, whereas the corresponding figure in the intervention group was $99 \%(10)$.

In the present study the amount of food wasted was reduced substantially. The explanation for this is probably a combination of the meals being more energy dense and the fact that the meals could to some extent be chosen by the individual patient. A similar finding has been reported from another study also focusing on energy density as well as the appearance of the serving (8). Finally, the patients in general reported a very positive attitude towards the new system. 
In conclusion, a change in the catering system, including an increase in the energy density, to a system where the patients can to some extent decide what they want to eat, and where the attention of staff is directed towards the significance of nutrition, results in increased energy and protein intake in patients with low intake and a substantial reduction in waste. It cannot be determined from the present study whether these change result in better outcomes for the patients. Thus, it would be of interest if other hospitals planning to implement similar changes could assess nutritional risk score, weight changes, morbidity or length of hospital stay before and after the implementation of a new catering system

\section{References}

1. ESPEN Education and Clinical Practice Committee. ESPEN guidelines for nutrition screening 2002. Clin Nutr 2003; 22: 415-21.

2. Stratton RJ, Green CJ, Elia M. Disease-related malnutrition: an evidence-based approach to treatment. Wallingford: CAB International; 2003.

3. McWhirter JP, Pennington CR. Incidence and recognition of malnutrition in hospitals. BMJ 1994; 308: 945-8.

4. Almdal T, Viggers L, Beck AM, Jensen K. Food production and wastage in relation to nutritional intake in a general district hospital - wastage is not reduced by training the staff. Clin Nutr 2003; 22: 47-51.
5. Kondrup J, Johansen N, Plum LM, Bak L, Larsen IH, Martinsen A, et al. Incidence of nutritional risk and causes of inadequate nutritional care in hospitals. Clin Nutr 2002; 21: 461-8.

6. Barton AD, Beigg CL, Macdonald IA, Allison SP. High food wastage and low intakes in hospitalised patients. Clin Nutr 2000; 19: 445-9.

7. Dupertuis YM, Kossovsky MP, Kyle UG, Ragusso CA, Gentoni L, Pichard C. Food intake in 1707 hospitalised patients: a prospective comprehensive hospital survey. Clin Nutr 2003; 22: 115-23.

8. Odlund-Nordin A, Isterberg P, Hadell K, et al. Energyenriched hospital food to improve energy intake in elderly patients. JPEN J Parenter Enteral Nutr 1996; 20: $93-7$.

9. Barton AD, Beigg CL, MacDonald IA, Allison SP. A recipe for improving food intake in elderly hospitalised patients. Clin Nutr 2000; 19: 451-4.

10. Johansen N, Kondrup J, Plum LM, Bak L, Nørregaard P, Binch E, Baesen Hisen H, Andersen JR, Larsen IH, Marlinsen A. Effect of nutritional support on clinical outcome in patients at nutritional risk. Clin Nutr 2004; 23: $539-50$.

\footnotetext{
Thomas Almdal, MD

Department of Endocrinology 541

Hvidovre University Hospital

DK-2650 Hvidovre

Denmark

E-mail: thomas.almdal@hh.hosp.dk
} 